\title{
Healthcare executives' readiness for a performance measurement system: a rehabilitation hospital case study
}

\author{
Diana Zidarov, Lise Poissant, Claude Sicotte \\ Universiy of Montreal, Canada
}

Correspondence: Diana Zidarov. Address: Centre de recherche, Institut de réadaptation Gingras Lindsay de Montréal, 6300 avenue Darlington, Montréal, Québec, H3S 2J4, Canada. E-mail: diana.zidarov@umontreal.ca

Received: April 28, 2014

DOI : $10.5430 /$ jha.v3n4p157

Accepted: June 5, 2014

Online Published: July 11, 2014

URL: http://dx.doi.org/10.5430/jha.v3n4p157

\begin{abstract}
The literature on organizational change identifies readiness as an important factor for understanding the outcome of implementation. In the context of implementing a performance measurement system (PMS) in a rehabilitation hospital, we conducted a case study to gain an in-depth understanding of the factors that might impede or facilitate readiness to use a PMS. Two data sources were used: key informant interviews with healthcare executives and official organizational documents. Our results indicate that healthcare executives' readiness for a PMS was high. This state of readiness is influenced by 12 factors that were classified into three main themes: (1) adopters' attributes, (2) PMS attributes, and (3) organizational attributes. These results are consistent with change management theory as well as the findings of recent empirical research. In the context of implementing a PMS, a readiness assessment can help identify organizational strengths and weaknesses so that strategies necessary for successful implementation can be developed.
\end{abstract}

\section{Key words}

Readiness, Health care administration, Organizations, Performance, Rehabilitation, Case study

\section{I ntroduction}

Rehabilitation hospitals, like any other healthcare organization, face persistent shortages of human resources, increased needs generated by an aging population and governmental demands of cost containment and accountability ${ }^{[1]}$. This situation places public healthcare organizations under increasing pressure to apply effective management tools. The development and implementation of performance measurement systems (PMS) in healthcare organizations has become an important mechanism for accountability and quality improvement initiatives ${ }^{[1-3]}$. Despite the general consensus on the need for PMS and its potential benefits ${ }^{[4,5]}$, the actual implementation of these systems remains challenging for organizations ${ }^{[6-9]}$ and involves significant organizational change ${ }^{[3]}$. Scholars in the performance measurement field ${ }^{[10,11]}$ recommend assessing the level of organizational readiness prior to implementing a PMS. The literature on organizational change also identifies readiness as an important factor in understanding the outcome of implementation ${ }^{[12-15]}$. When implementing a PMS, a readiness assessment can help identify organizational strengths and weaknesses and the strategies necessary for successful implementation ${ }^{[16]}$. Although there is no consensus on a single definition of "readiness for change" ${ }^{[17]}$, the following definition, proposed by Armenakis and colleagues ${ }^{[14]}$, is the most commonly cited: 
“organizational members' beliefs, attitudes, and intentions regarding the extent to which changes were needed and the organization's capacity to make those changes". The literature suggests that readiness for change is influenced by the attributes of the change (what the change is about and its content), the attributes of the context (where and under what circumstances the change is occurring) and the attributes of individuals (who are involved in the change) ${ }^{[14,17,18]}$. More specifically, the most important attributes of the change that influence readiness is the perceived need for change, the appropriateness of the change as a solution to a specific problem ${ }^{[14]}$ and the characteristics of the change (e.g. perceived advantage, level of complexity, and degree of adaptability of change to meet local needs) ${ }^{[19]}$. Factors related to the organizational context that influence readiness include availability of resources, effective leadership, access to information/training ${ }^{[19,20]}$, active participation, quality of change communications, rewards and incentives, culture and climate $^{[18,20,21]}$. Individual factors that may influence readiness refer to organizational members' attitudes, beliefs, intentions, motivation, knowledge and competence regarding a proposed change ${ }^{[17,18]}$.

Currently, there is no comprehensive theory or framework of readiness for change that specifies which dimensions or factors must be assessed when studying this construct ${ }^{[17,18,20,22]}$. Given these considerations, qualitative research methodology appears best suited to fully capture and describe the readiness of intended users for a PMS. In the context of this study, readiness to change refers to the healthcare executives' beliefs, attitudes and intentions regarding the extent to which a PMS is needed and the organization's capacity to successfully use such a system ${ }^{[14]}$. Our objective was to identify the main readiness factors that affect the willingness to use a PMS in rehabilitation healthcare organizations.

\section{Methods}

\subsection{Study design}

We conducted a single case study to gain an in-depth understanding of the factors that might impede or facilitate readiness to use a PMS. The case under study is a rehabilitation hospital in Canada that developed and implemented a PMS. The study was undertaken during the PMS implementation just prior to its use.

\subsection{Organizational setting and case description}

The setting is a typical mid-size publicly-funded urban academic rehabilitation hospital in Canada. The organization provides specialized care and rehabilitation services to adults with physical disabilities. In 2010, an extensive consultation process to develop a five year strategy plan was undertaken. One of the main strategic objectives was the development and implementation of a PMS. The development of the PMS began in 2011 and lasted 18 months. Overall, the PMS included 30 performance objectives, 43 indicators, time frames and data collection dates. The intended users of the PMS are healthcare executives and hospital board members.

\subsection{Data sources}

Two data sources were used: key informant (KI) interviews with rehabilitation hospital executives and official organizational documents. Respondents were selected for their involvement in the development and/or role as an end-user of the PMS. In September and October 2012, face-to-face interviews were held in the hospital with seven key informants. The interviews, which lasted between 60-90 minutes, were audio-recorded and transcribed. Interviews were conducted by the first author. The interviewer is a physiotherapist working in the organization who was familiar with the study context, an advantage in qualitative studies ${ }^{[23]}$. A discussion guide was developed based on current knowledge of theories on organizational readiness ${ }^{[14,15,17,18,24]}$ and on the implementation of innovations ${ }^{[19,25]}$. We asked KIs open-ended questions on their conception of a PMS and their perceived need, motivation, experience and knowledge about it. Organizational context factors such as prioritization of implementation of the PMS, dedicated resources and organizational processes related to implementation were also explored. Written consent from each KI was obtained prior to interview. A total of 70 official documents (annual reports, strategic planning, minutes from hospital board and executive meetings) produced 
between January 2011 and June 2013 were reviewed to provide organizational and contextual information to complement data obtained from interviews.

\subsection{Data analysis}

Each interview transcript was verified for accuracy and then imported into qualitative analysis software (QDA Miner 3.2.3). A mixed approach for content analysis was used (deductive and inductive coding processes) ${ }^{[26-28]}$. The first step was to create a provisional guiding framework and a coding list prior to initiating coding (see Table 1). This list emerged from our interview guide and the review of readiness to change models ${ }^{[15,17,18,21,29]}$ and implementation frameworks ${ }^{[19,25]}$. According to Miles and Huberman ${ }^{[30]}$, creating provisional codes can help researchers include concepts already known in the existing literature. The initial coding was done by the primary author who has experience in qualitative analysis. All transcripts were read line by line. Initial coding was done by identifying sections of text that related to themes from the provisional coding list or that emerged from the data ${ }^{[27]}$. When new codes emerged, the coding frame was changed and the transcripts were re-read according to the new structure ${ }^{[31]}$. This process was used to develop categories, which were then grouped into broad themes for each interview. Regular consultations were held among researchers during the coding and interpretation of the data to ensure its appropriateness. Disagreements were discussed by comparing the verbatim with the operational definitions of the various constructs and a consensus was reached. This approach allowed for an in-depth analysis of each of the seven KI interviews and to acquire a final coding framework. This final coding framework was then applied to code the relevant sections from the organizational documents. A comparative analysis between each KI interview was then conducted and an explanatory matrix ${ }^{[30]}$ was produced to appraise if a given category seemed to be positively or negatively related to readiness for change. This overall appraisal was made according to the level of agreement among respondents on a given subject or the number of respondents who had or not a given attribute. If four or more KIs agreed, or had a given attribute, the category was judged as a positive contribution to the organizational readiness.

Several methods were used to increase the confirmability of our results ${ }^{[32,33]}$. The authors met regularly throughout the analysis phase to discuss progress and findings and the results were reviewed by the authors to minimize any interpretation biases. To increase credibility, we used two triangulated data sources. The results were also orally presented to key informants followed by a discussion about data interpretation. Respondents then agreed that our interpretation corresponded to what they meant to say. Furthermore, to ensure dependability, a research protocol was written prior to the study, software was used to code transcripts and document coding decisions and a codebook with code definition was produced and used when analyzing transcripts.

The research protocol was approved by the research centre ethics review board.

Table 1. Provisional guiding coding list

\begin{tabular}{ll}
\hline Themes & Provisional categories \\
\hline & Gender \\
Age \\
Tenure \\
Education \\
Adopters' attributes & Self-efficacy \\
& Knowledge and beliefs \\
& Motivation \\
Attitude \\
Organizational commitment \\
\hline
\end{tabular}

(Table continued on page 160) 
Table 1. (continued.)

\begin{tabular}{|c|c|}
\hline Themes & Provisional categories \\
\hline \multirow{9}{*}{ PMS attributes } & Tension/need for change \\
\hline & Appropriateness for change \\
\hline & Type of change: radical vs. incremental \\
\hline & Pressure for change: external vs. internal \\
\hline & Relative advantage \\
\hline & Complexity \\
\hline & Adaptability \\
\hline & Trialability \\
\hline & Design quality \\
\hline \multirow{12}{*}{ Organizational attributes } & Vision and goals \\
\hline & History of change \\
\hline & Organizational conflicts \\
\hline & Participative management \\
\hline & Leadership \\
\hline & Relative priority/competing demands \\
\hline & Project leader \\
\hline & Credibility of project leader \\
\hline & Information/training \\
\hline & Rewards/recognition \\
\hline & Dedicated time and resources \\
\hline & Quality of communications \\
\hline
\end{tabular}

\section{Results}

\subsection{Characteristics of key informants}

Four KIs were women. The median age of the KIs was 52 years (ranging from 35 to 69 years) and all had university degrees ( 2 bachelor's degrees, 3 master's degrees and 2 doctorate degrees). Their experience in the organization under study varied between 2 months and 25 years.

\subsection{Themes}

Our analysis of the data yielded a rich description of the factors involved in healthcare executives' readiness to use a PMS. Twelve factors emerged from the data and were classified into three main themes: (1) adopters' attributes; (2) PMS attributes and (3) organizational attributes. Each factor is described in detail in Table 2 and an overview of its impact (positive or negative) on readiness of healthcare executives to use a PMS is given in Figure 1. Factors are discussed in greater detail below with illustrative quotations drawn from the data sources.

\subsubsection{Adopters' attributes}

The individual attributes of healthcare executives and the differences in these attributes may influence differently their readiness for a PMS. Four factors, some of them interrelated, emerged from the data: prior experience with a PMS, self-efficacy, intention to use the PMS and perception of team's resistance to PMS. All of these factors, excepting the perception of team's resistance to the PMS, were positively associated with healthcare executives' readiness to use it. 
Table 2. Description of themes and categories identified from individual interviews and from the analysis of organizational documents

\begin{tabular}{|c|c|}
\hline Themes and categories & Brief description \\
\hline \multicolumn{2}{|l|}{ Adopters' attributes } \\
\hline Prior experience & $\begin{array}{l}\text { Qualifications of adopters with PMS shown by any studies related to this topic or by } \\
\text { any previous work experience with this subject }\end{array}$ \\
\hline Self-efficacy & Individual belief in one's own ability to develop and use a PMS \\
\hline Intention to use & Adopters' interest or intention to use the PMS \\
\hline Perception of the team's resistance to PMS & $\begin{array}{l}\text { Team level perceptions of opposition or unwillingness of adopters to change their } \\
\text { behavior }\end{array}$ \\
\hline \multicolumn{2}{|l|}{ PMS attributes } \\
\hline Content & $\begin{array}{l}\text { Identification of PMS content (type of indicators to be included, developmental } \\
\text { process) }\end{array}$ \\
\hline Perceived usefulness & Adopters' perception of the usefulness of the PMS \\
\hline \multicolumn{2}{|l|}{ Organizational attributes } \\
\hline Need for PMS & The degree to which adopters perceive a need for a PMS \\
\hline Participative management & $\begin{array}{l}\text { The extent to which employees are consulted, involved in and informed in } \\
\text { organization's decision making process }\end{array}$ \\
\hline Leadership engagement & $\begin{array}{l}\text { Formal commitment, involvement and accountability of CEO and management team } \\
\text { with the adoption of the PMS }\end{array}$ \\
\hline Relative priority & $\begin{array}{l}\text { Importance of the adoption and development of a PMS within the organization } \\
\text { compared to other competing priority projects }\end{array}$ \\
\hline \multicolumn{2}{|l|}{ Organizational support } \\
\hline Project leader & $\begin{array}{l}\text { Formally appointed individual with the responsibility of developing and } \\
\text { implementing the PMS }\end{array}$ \\
\hline Dedicated time and resources & $\begin{array}{l}\text { Available means needed to develop and implement a PMS (e.g. information } \\
\text { technology) }\end{array}$ \\
\hline Formal management processes & $\begin{array}{l}\text { Existence of formal systematic processes to integrate the PMS development and } \\
\text { implement it into existing routines and procedures }\end{array}$ \\
\hline
\end{tabular}

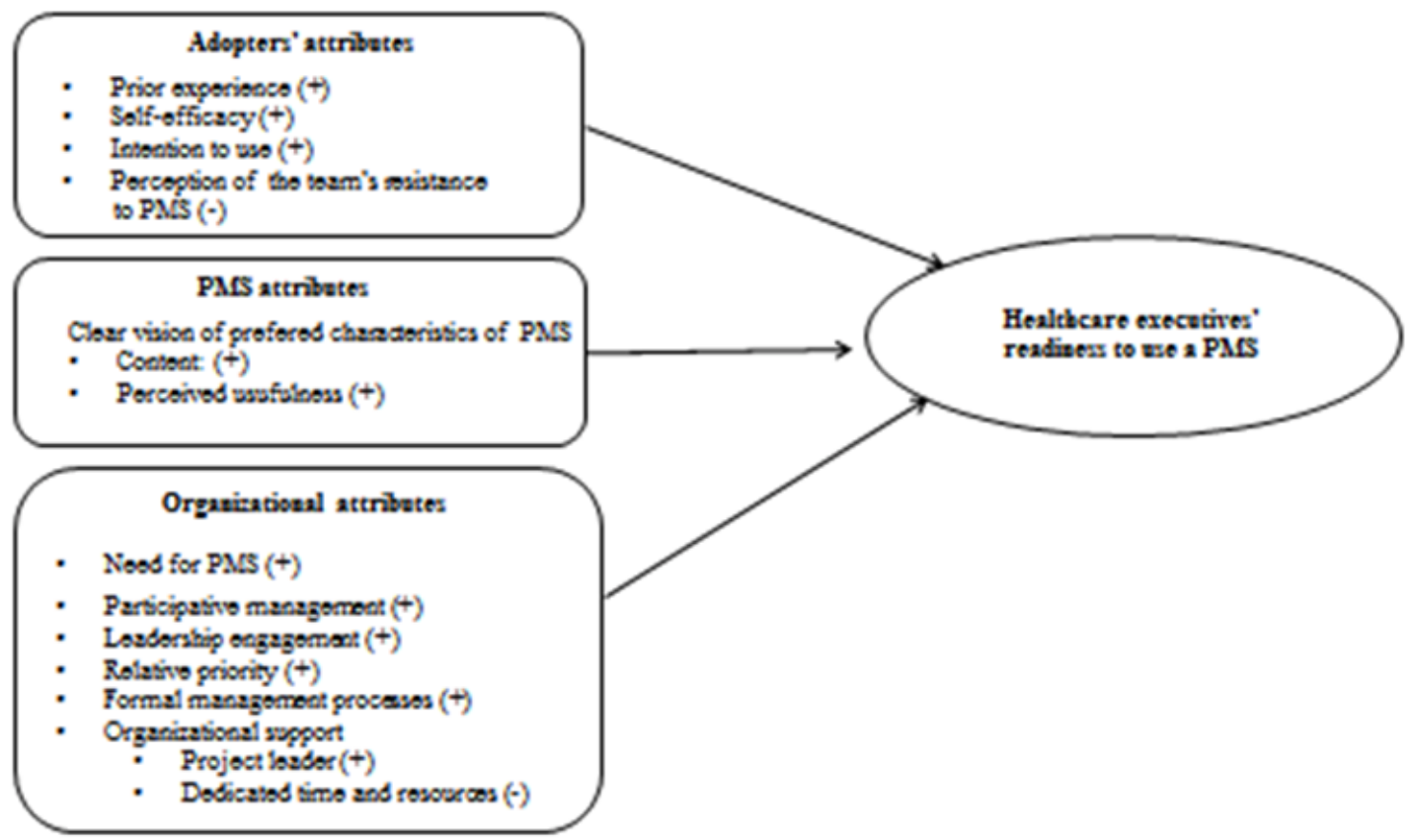

Figure 1. Summary of positive and negative factors associated with healthcare executives' readiness to use a PMS 


\section{(1) Prior experience}

Six respondents had previous experience with the use of some kind of performance management tool. Furthermore, three respondents had direct experience in the development of management tools (e.g.: dashboards) that use indicators. Overall, the respondents had a prior knowledge of PMS (related to their level of education or from current/previous work experience) and this was found to be positively associated with their readiness to develop and use a PMS.

“The whole question of indicators and continuous improvement, I’m quite familiar [with them]... very familiar ... anyway, I worked with those tools and I also believe in them. As a director, I produce an annual improvement plan that includes indicators.” (KI 2)

\section{(2) Self-efficacy}

Six KIs seemed confident in their ability to use a PMS. This high perception of self-efficacy was associated with prior experience with a PMS. One respondent seemed less confident in his ability to carry out this change (mainly due to the challenge of coping with the ongoing many changes taking place in the organization).

"Recently, there have been many changes in my direction and there are more to come. [...] so at some point, people like me, who are responsible for making these changes, no longer have the physical or psychological ability to do it.” (KI 5)

\section{(3) Intention to use}

All KIs expressed intention to use the PMS: "I would be willing to use the PMS if the information obtained goes beyond simply observing facts. It has to allow for a thorough analysis and lead to concrete organizational actions” (KI 5). Another respondent said: "For the hospital board, access to the tool will allow us to follow the evolution of the organization and also make better decisions" (KI 7). Intention to use was also associated with certain characteristics that respondents would like the PMS to have, specifically a broad array of readily available indicators and the possibility of using the PMS as a tool to support decision-making.

\section{(4) Perception of team's resistance to PMS}

Although all the respondents expressed motivation and intention to use the PMS on an individual level, they perceived that on the team level, not all executives were open to that change. Some respondents anticipated resistance from colleagues, believing they would prefer to see the development and use of the PMS delayed because of the organization's current organizational context - namely budgetary constraints and change overload. Others believed that some of their colleagues would lose power owing to the fact that executives would have the ability to question the indicators under their control. Others believed that some of their colleagues would worry that underperformance could negatively influence their operating budget. For all these reasons, the perception of team's resistance to the use of a PMS was negatively associated with health executives' readiness for this change.

"I think there are some directors who really see it (the PMS) as a control tool which will result in less flexibility and leeway in their direction to organize their business. I think that some directors are at this stage. You know sometimes, you don't like to be questioned about your resources, what you do with them and how you could do it differently.” (KI 4)

\subsubsection{PMS attributes}

Health care executives' readiness for a PMS was positively influenced by their shared vision of certain attributes that the PMS must have - namely its content and its perceived usefulness.

\section{(1) Content}

The majority of respondents agreed on the general content of the PMS. The respondents unanimously wanted a small set of diverse and readily available indicators (i.e. mostly clinical, human resources and financial indicators). All favored both 
the individual and collective development of indicators. Useful, relevant and available indicators within each department could be proposed for adoption at the Executive Committee. This type of process would create a pool of prioritized and selected indicators by consensus from the executive board in light of the organization’s goals.

"Each director must do their own reflection, but then again I think it should go up to the Executive Committee. It is the role of the committee to share, sort out the indicators, and establish which ones are the most reliable. A consensus should be a prerequisite for the organizational goals that take place at the executives' meetings. I see it as teamwork, otherwise there is a risk that it will create silos with each director working with their own objectives and projects in mind and not necessarily those of the organization.” (KI 6)

\section{(2) Perceived usefulness}

Six KIs expressed positive beliefs about measuring performance and systematically using performance indicators. For example, one respondent said: "For me, measuring performance is unavoidable. We have to move forward because we are well behind other healthcare organizations on this matter" (KI 3). Another one said: "It is important to measure our organization's performance and demonstrate our specificity objectively because there is a risk that the Ministry of Health will compare our organization with hospitals that do not have the same mission or structure of care” (KI 1).

Respondents also perceived the PMS as a tool that could be useful for decisional support by providing objective data in a timely manner: "It could be an incredible tool for decision making. I'm telling you, if we had it every month, the data could provide us with excellent possibilities for analysis” (KI 1). The PMS could also be useful for improving services, clinical processes and process management. These benefits would be achieved through the rapid detection of deviations from planned targets and the possibility, over the long term, to make internal comparisons of performance through the accumulation of data over the span of many years.

"When we can compare our current organization with data from previous years, we may detect that we have used processes that are less efficient that those previously used. Maybe we will need to change some of these by implementing more computers in some of the clinical practices or by implementing other technology. The point is that when there are no comparisons and no performance indicators, nobody asks any questions and we all function as usual.” (KI 6)

Conversely, one key informant expressed doubt about the real impact of this type of PMS in organizational improvement and the limited influence of this type of data for negotiating or persuading governmental authorities - which was one important goal of this change initiative.

"Will the fact that these indicators are available and compiled change anything in decision-making? Were they chosen because we had to choose some? What it will allow us to do or what decisions will it allows us to make? We can make measurements in the organization, but physical rehabilitation is a really small proportion of health budgets. So, there is not so much we can do... still, we would collect our own performance indicators but if they are not standardized or accepted by the Health Ministry, they will not be considered and won't have much of any impact.” (KI 5)

\subsubsection{Organizational attributes}

Certain conditions in the organization's environment were important determinants for the readiness of healthcare decision makers to use a PMS. Six factors emerged with regards to the organizational environment: need for a PMS, participative management, formal management processes, leadership engagement, relative priority of the PMS, and organizational support. All these factors, except for a lack of organizational support for dedicated resources to PMS development and implementation, were positively associated with executives' readiness to use a PMS.

\section{(1) Need for PMS}

All KIs expressed the need for a centralized, systematic and relevant data system to support timely and informed decision making. All KIs expressed that important changes in top management (i.e. chief executive officer and several executives) 
and major budgetary cuts were required to avoid a financial deficit. They felt these were the two main events that contributed to the need for the use of a PMS in inefficient systems. This perceived need for a PMS was associated with the intention to use the PMS.

"If we do not want to cut services, if we do not want to reduce the amount and the quality of services in particular, we have to do things differently. How can we do things differently if we have no indicators on the way we actually do things?” (KI 3)

\section{(2) Participative management}

Participative management is the consultation of employees on decisions that may affect them. Executives, managers and health professionals were all consulted during the development of strategic planning initiative that included the goal to develop and implement a PMS.

"It (the PMS) was an intention that emerged from various consultations and it was embodied in the strategic planning. [...] My opinion is that it was pretty consensual.” (KI 1)

Furthermore, participative management through frequent consultation processes is a well-established organizational practice as illustrated by this KI's comment:

"For example, we developed and drew up a consultation process to define our annual objectives. [...] we use this approach every year to ensure prior consultation with all of the organization's relevant committees such as the Executive Committee, with all middle level managers, professional committees and the user’s committee.” (KI 1)

Other organizational documents (strategy plans, annual reports, minutes from executive meetings and internal web publications) confirmed that participative management is well-institutionalized. For example, in the 2012-2013 annual report, we found the following: "Note that the common denominator of our projects and the achievement of our goals is the improvement of the quality of services by a philosophy of participatory management involving key stakeholders, managers, clinicians and users (patients)". In short, participative management has ensured a consensus among different stakeholders, including healthcare executives, on the development and implementation of a PMS which is positively associated with readiness.

\section{(3) Formal management processes}

Aside from participative management, the development and the implementation of the PMS was facilitated by the existence and use of formal management structures that not only supported participation but also played a role as a regulatory mechanism and for accountability. For instance, the Executive Committee meets for three hours, twice a month. These meetings are governed by rules of procedure adopted by the Executive Committee. Each director may add items to the agenda provided that it concerns a priority objective or requires consultation/decision-making on the organizational level. This allows for the participation and involvement of all executives in the development of the PMS. The analysis of the minutes of the Executive Committee meetings held at the end of 2012 revealed that the PMS was discussed at three consecutive meetings and decisions were made concerning its development, namely the prioritization of organizational objectives and the selection of performance indicators.

Another formal structure is the hospital board. The hospital board holds between five and six meetings annually. Hospital board meetings are mandatory, and are an important accountability mechanism for the hospital's executive board. At these meetings, various priority organizational issues are tracked, discussed and decisions are made accordingly. Following its adoption in December 2012, the PMS was on the hospital board's agenda at each meeting and was discussed each time. These management formalities exist to closely monitor the development and implementation of the PMS. Any deviation from what was planned will be discussed at the executive and the hospital board meetings hence the positive association of between these formal structures and the healthcare executives' readiness for a PMS. 


\section{(4) Leadership engagement}

All respondents agreed that the CEO is the person with the most authority to further the use of the PMS.

"The message starts with the CEO. He establishes the organizational priorities. The CEO will say, "Okay, now, executive board, your priority project is the PMS. Then the focus will be placed on the project like any other project we've done." (KI 3)

The CEO's commitment to this project was demonstrated by its actions and decisions, all of which were recorded in the minutes of the executive and/or hospital board meetings. Management engagement for the PMS was demonstrated by the consensual choices that were made by the Executive Committee about the organizational goals and the means to achieve them. These included the choice of developing and implementing a PMS. The goals were also adopted by the Hospital Board which implies that the Executive Committee was accountable for its implementation. The leadership's engagement for all decision-making was also confirmed by the 2011-2012 and 2012-2013 annual reports, the reports of the hospital board and the minutes of the Executive Committee. The engagement of leaders and management was therefore clear and positively associated with their readiness to use a PMS.

\section{(5) Relative priority}

The KIs described the development and implementation of a PMS as a priority for the organization. However, while describing the project as a priority, KIs also diminished the expectancies by saying that developing and implementing a PMS in the short term would be "difficult under the current organizational context" as the organization was currently experiencing a challenging financial environment that was creating competing priorities. Further, a major administrative reorganization took place that resulted in the abolition of eight senior positions. Several executives were affected by this restructuring. This issue was identified by KIs as an important threat to the implementation success and use of the PMS.

"Although we all feel a strong need to have meaningful indicators, I think that right now, we have to choose which projects to carry out and most importantly, to provide support for our colleagues who are the most affected by the structural changes.” (KI 2)

Despite this major restructuring, the new executive board decided to keep the PMS as an organizational priority and as a 2012-2013 project. These events show that the relative priority of the PMS has fluctuated since the decision to adopt it in 2011 despite several competing priorities and organizational events. However, the priority of this project remained and the PMS development restarted in October 2012. For these reasons, we believe that the level of high priority given to the PMS prevailed and therefore was positively associated with readiness to change.

\section{(6) Organizational support}

We identified two sub-categories related to organizational support: assignment of a project leader and allocation of time and resources.

\section{(7) Project leader}

All respondents expressed the necessity to have a project leader responsible for coordinating the development and implementation of the PMS including the collection and centralization of data into one information system. This support was perceived by the KIs as being essential to the success of the PMS project once the project leader finalized the PMS development and began its implementation.

"You know, organizational projects require a project leader. The role of the project leader is to follow-up. So, if part of the Executive Committee's agenda is to have a statutory point which is to monitor the dashboard indicators, we know that the project leader will be reporting." (KI 3) 


\section{(8) Dedicated time and resources}

All respondents agreed that, because of the organization's financial situation, no new resources could be invested in the development and implementation of the PMS. Regardless, this project prevailed and was carried out by reorganizing work among existing structures.

"I think that we will need to reorganize our ways of doing things and integrate the PMS into our operations. I see it as a project that we will be integrating into our way of working rather than the need to add resources. The project leader has tasks other than this project (the PMS), but it is his role to ensure that it proceeds on schedule. We already have a monthly individual meeting with the CEO so that subject (the PMS) can be discussed. We have bi-weekly Executive Committee meetings and it will be a recurring theme in the agenda. Then of course, there is also the hospital board. So for me, monitoring the advancement of this project will be done in the same way as it would for any other organizational project”. (KI 1)

The KIs reported having a work overload and other priorities to address due to the administrative reorganization in each direction and a lack of time to develop the desired PMS.

"The other barrier, you know, is the lack of time to develop and choose the right indicators. It is easier, or less demanding, to work "as usual" without making too many changes or make too much effort. Even I have to say ... you know, it is not easy to find original indicators and there are indicators that have already proven their worth. We know where to find them and it does not require more work for our teams.” (KI 2)

KIs also addressed the issue of information systems (IS). Having an efficient IS was seen as an essential prerequisite for gathering reliable and complete information. Efficiency was defined by KIs as compatible systems between departments and the automated extraction of relevant PMS data.

"So for me, a big barrier is the information systems. Do we have the right information systems? Do we, or will we, have the information systems required to get the relevant information?” (KI 4)

For all those reasons, resources seem to be insufficient and may have a negative influence on readiness.

\section{Discussion}

To our knowledge, this is the first study to explore the individual and contextual factors that influence the readiness of a rehabilitation hospital in the use of a PMS as part of a planned incremental administrative change ${ }^{[34]}$ for performance management. Our results showed that healthcare executives' readiness for a PMS was high. Our data analysis has revealed twelve factors that influence readiness for a PMS. Ten of these factors have contributed positively to the readiness for a PMS. However, our results do not allow us to determine the relative importance or identify the "right" combination of factors that may predict high or low readiness for change. However, these factors are consistent with readiness theories and frameworks. They show that readiness for change is the result of the interaction between individuals involved in the change, the attributes of a given change and the context in which the change occurs. In what follows, the themes and their associated factors will be discussed in greater detail.

\subsection{Adopters' attributes}

Healthcare executives' attributes are important factors that positively contributed to PMS readiness. Furthermore, those factors seemed to be interrelated. All respondents reported having some experience with the use of a more or less complex PMS and claimed to have seen organizational benefits resulting from this use. Additionally, this prior experience seems to have contributed to the high self-efficacy of healthcare executives. In fact, they felt competent and capable of contributing to the development and the implementation of the PMS. This is in accordance with Bandura's ${ }^{[35]}$ Social Learning Theory 
which posits that past experiences with a specific change contributes to the development of self-efficacy. In an empirical study by Rafferty and Simons ${ }^{[36]}$, where they investigated the factors that influence individual readiness for smaller incremental change as opposed to major and more disruptive change, they found that self-efficacy was one of the critical factors associated with both types of change. This means that strategies to develop the person's belief regarding their own ability to carry out the change may significantly enhance their readiness for change.

A surprising finding was the absence in the respondents discourse about resistance to change at an individual level. We found instead a perception of collective resistance by the executives once the PMS would be in use. In our study, this perception of collective resistance to change was negatively associated with the readiness for a PMS and was mainly expressed by respondents as a fear of losing power. In fact, before implementation of the PMS, the sharing of certain information depended on each executive's decision. With the implementation of the PMS, access to information should be more evenly distributed and was perceived as a threat by some executives. People may be resistant to change not because of the change itself, but because of a perception of a certain later loss caused by the proposed change ${ }^{[37]}$.

In the literature, resistance to change is considered as one of the most important impediments that explain the failure of organizational change initiatives ${ }^{[38]}$. Consequently, it is of great importance for an organization to be on the lookout for any behavior that may indicate resistance. Resistance can manifest itself as conduct that affects the change process (e.g. that delays or slows its development, obstructs or hinders its implementation or that encourages the status quo) ${ }^{\text {[38] }}$. Resistance to PMS can be reduced through the promotion of open communication, understanding and dialog ${ }^{[10,39]}$. Communication and timely communication in particular, is considered to be a key mechanism for the effective implementation of organizational change ${ }^{[40,41]}$ by increasing openness and commitment to change and by reducing resistance ${ }^{[42]}$. Leaders can use various communications channels to remind change adopters of the organization's goals in relation to the development and implementation of the PMS and the expected benefits that this change will entail. Furthermore, fostering an environment that allows for experimentation, innovation ${ }^{[43,44]}$ and learning rather than blame ${ }^{[45,46]}$ can also contribute to reducing the adopters' resistance to PMS. Furthermore, designing and implementing a PMS is a complex task that requires specific knowledge and expertise ${ }^{[3,47]}$. Development opportunities and training ${ }^{[39]}$, as well as educating all intended PMS users about the appropriate interpretation of the information gathered through the PMS ${ }^{[48]}$ may contribute to reducing resistance and enhancing ownership and commitment for the performance measurement.

\subsection{PMS attributes}

Other key factors found in our study that seems to play an important role in the level of readiness for change, and ultimately for the success or failure of implementation ${ }^{[15,24,29]}$, was the respondents' shared vision of the important characteristics that the PMS must have (mainly related to its content and usefulness). This consensus regarding the attributes of the PMS was a somewhat surprising finding given that the actual executive team had worked together for little more than a year. One reason may be that, as previously mentioned, all of the executives had previous experience with the use of a PMS. This type of similar experience may have contributed to the development of similar interpretations about what the changes should be ${ }^{[42]}$. Another hypothesis may be that the CEO, as a leader, had developed a clear vision about performance measurement and had successfully transmitted it to the other executives who then integrated it and adapted it to fit their own beliefs ${ }^{[42]}$. Such shared vision was sustained by the healthcare context in which all health organizations, including rehabilitation organizations, evolve. The Ministry of Health had established performance evaluation of the public health system and social services as one of its priorities. This stance was outlined in several governmental documents published on the topic including the 2010-2015 strategy plan and the publication of a ministerial framework for the performance evaluation of public health system and social services. The omnipresence of the issue of performance in the current healthcare context therefore made decision-makers highly aware of this topic and consequently, they were more ready to address this issue one way or another. Thus, a clear vision is another key factor that can enhance readiness ${ }^{[49]}$. Without a clear vision, the effort for change can easily degenerate into a series of diverse and not always compatible projects. It can even send an organization in a direction where it does not want to go ${ }^{[50]}$. 


\subsection{Organizational attributes}

Organizational readiness was influenced by the healthcare executives' collective perception of PMS attributes and several organizational attributes that were interrelated with the PMS attributes. Healthcare executives reported that a PMS was indispensable in their current healthcare and organizational context. If a change do not match the needs of the organization, implementation is jeopardized; even if the resources and readiness are favorable ${ }^{[20]}$. Without the belief by adopters that there is a gap between the organization's current state and what is hoped to be a better state, there will be no full adherence to the change ${ }^{[15]}$. In our study, the need for a PMS was stated as being necessary for each direction as well as on the whole organizational level. This need was expressed by all respondents and was triggered by major budgetary pressures that required objective information in order to make informed decisions. The need was reinforced by the repetitive demands of healthcare authorities for objective data and information. In an empirical study of factors affecting the adoption and implementation of performance measures, de Lancer Julnes and Holzer ${ }^{[47]}$ found that when performance measure policy came from within the organization as an internal requirement or need, the performance measures are more likely to be adopted. Indeed, the adoption of the PMS would not have progressed beyond this stage without the strong leadership engagement of the CEO who highly prioritized the project among competing projects and offered continuous organizational support.

\subsubsection{Leadership engagement}

Leadership engagement is an essential factor that contributes to preparing organizations for change by creating a commitment to change ${ }^{[51]}$. In addition, leadership engagement has also been recognized in several systematic reviews as a core factor that influences the adoption and successful implementation of innovations ${ }^{[25]}$, quality improvement initiatives ${ }^{[52]}$ and the use of performance information ${ }^{[53]}$. In our study, the leadership and commitment of the CEO was essential for moving from development to implementation of the PMS. It was also a key component in an organizational context that was facing significant change. Competing priorities seems to be a common issue for healthcare organizations and the intensity of these demands may positively or negatively impact the implementation of change ${ }^{[54,55]}$. In our study, the priority given to the PMS fluctuated since its adoption in 2011 until the CEO and the executive team agreed that the timing was appropriate to initiate implementation. The CEO's leadership, personal vision and beliefs about performance measurement were also central in triggering the initiation of PMS development. It should also be noted that the current CEO was not yet in office when the PMS was initially adopted. Notwithstanding this, the CEO committed himself to the project and contributed to rallying the Health Board and the executives around his vision of the PMS. Besides, the short tenure of the CEO (15 months at the time of the interviews) may be a factor explaining the engagement of executives and the organization in this project. For instance, a CEO with only a brief tenure in office may be more flexible and perceive the external and internal organizational environment differently and see more strategic options available when compared to a CEO with a longer tenure who may become more committed to a given paradigm of how the organization should be run ${ }^{[34,56]}$.

\subsubsection{Organizational support}

CEO leadership and commitment to the PMS project resulted in true organizational support by allocating resources to the project (namely the designation of a formal project leader to manage the project). Executives were also asked to allocate time to work on developing and implementing the PMS. Nevertheless, they complained that they lacked sufficient time to reflect upon and develop the PMS because of their other tasks. In the literature, several reviews found that if the allocation of resources is adequate, the implementation of change will succeed ${ }^{[25,34]}$. More specifically, in the performance field, the provision of adequate resources contributes to the use of performance measures ${ }^{[47,57]}$. In our study, dedicated time and resources seemed insufficient and may therefore negatively influence the readiness for a PMS. However, it is difficult to predict the actual impact of an inadequate provision of resources on the success of implementation. In two recent studies ${ }^{[58,59]}$, the intended change was successfully implemented despite the limited availability of resources which suggests that the negative influence of this factor can be reduced by the presence of other factors that have a positive impact on implementation. 
In another line of thought, our study found that participative management and existing management processes acted as enablers to the development and implementation of the PMS. Participative management allowed for the involvement of all executives across all stages of PMS development; from prioritization of organizational objectives to the choice of indicators and targets. Through participation, executives were able to contribute to important decisions and gradually build the skills and the knowledge necessary to effectively develop the PMS. This approach may have enhanced their self-efficacy and they collective commitment to the PMS project ${ }^{[40]}$ which follows the same line of thought as other research including Inamdar et al. ${ }^{[11]}$ who stated that the single most important factor for the successful implementation of PMS is the involvement and ownership of the executive team. In a recent narrative systematic review on the dissemination of performance information ${ }^{[53]}$, participation was reported to have numerous benefits such as having positive influence on the perceived quality, credibility, legitimacy and usefulness of the developed PMS. Furthermore, participation appears to foster collective learning and enhance the commitment of PMS users.

In the case under study, the participation by executives was facilitated by the formal management processes that already exist in the organization. It also fitted with the participative management style adopted. The bi-monthly meetings held by the executives were a great opportunity to interact, share information and discuss different topics, including the PMS. This mechanism may also have contributed to the development of shared perceptions regarding organizational issues ${ }^{[60]}$ which is fundamental for the promotion of readiness.

\subsection{Study limitations}

A limitation of our study is the study design. We conducted a single case study and interviews were conducted over a single point of time. Thus, our results reflect the perception of respondents at that particular time. These perceptions may have differed if the interviews had been carried out at another point in time. However, the time frame for assessing readiness is narrow. To ensure greater accuracy of its measurement, it should be assessed as close as possible in time before implementing a change ${ }^{[17]}$. In our study, interviews were carried out three months prior to use of the PMS. Furthermore, we investigated a complex concept (readiness for change) and capturing all its facets in a single study is a challenging goal. Our study was conducted in a typical North American rehabilitation hospital in a public-funded health system. This specific environment should be taken into account before transferring our results to other types of organizations or health systems' governance. A multiple case study design may reveal other factors and might contribute to a more comprehensive understanding of decision makers' readiness for a PMS. While generalization from our single case study is limited ${ }^{[61]}$, the transferability of our findings is feasible and even reinforced because of the detailed description of the case and context, that allow readers to extract the information relevant to their setting ${ }^{[62]}$. Finally, an analytical generalization ${ }^{[61]}$ might be made concerning the factors found in our study that influence readiness for a PMS. In fact, these factors are corroborated by frameworks/theories and by empirical research on readiness for change as well as by different settings and diverse changes.

\section{Conclusion}

Our findings contribute to a limited body of research on the organizational context of readiness for change in rehabilitation health care settings. Our results indicate that readiness for a planned incremental administrative change, namely a PMS, is influenced by the attributes of the intended users of that PMS, the attributes of the PMS and the attributes of the organizational context in which the PMS will be implemented. The factors found in our study are corroborated by several other studies addressing readiness for change, no matter what the change was, the individuals affected by this change and the context in which the change took place. Nevertheless, the positive or negative influence of these factors is specific to a particular setting and must be assessed prior to implementing a change in order to develop organizational and individual specific strategies to optimize readiness for that change.

\section{Acknowledgements}

We gratefully acknowledge the involvement of all study participants. 


\section{Competing interests}

The authors declare that they have no competing interests.

\section{References}

[1] McDavid J, Huse I, Hawthorn L. Program Evaluation and Performance Measurement: An Introduction to Practice. 2 ed. Thousand Oaks, CA: SAGE Publications. 2013; 560.

[2] Kanji G, Moura e Sá P. Sustaining healthcare excellence through performance measurement. Total Quality Management \& Business Excellence. 2003; 14(3): 269-89. http://dx.doi.org/10.1080/1478336032000046607

[3] Adair CE, Simpson L, Birdsell JM, Omelchuk K, Casebeer AL, Gardiner HP, et al. Performance Measurement Systems in Health and Mental Health Services: Models, Practices and Effectiveness. A State of the Science Review. The Alberta Heritage Foundation for Medical Research. 2003

[4] McIntyre D, Rogers L, Heier E. Overview, history and objectives of performance measurement. Health Care Financ Rev. 2001; 22(3): 7-21.

[5] Mayer J. Performance measurement: an essential component of medical practice. Med Group Manage. 1999; 46(6): 12-4.

[6] Thompson B, Harris J. Performance measures: Are we measuring what matters? Am J Prev Med. 2001; 20(4): 291-3. http://dx.doi.org/10.1016/S0749-3797(01)00294-X

[7] Baker G, Brooks N, Anderson G. Healthcare performance measurement in Canada: Who's doing what? Hospital Q. 1998; 2(2): 22-6. PMid: 10621171.

[8] Fondation canadienne de la recherche sur les services de santé. Performance reporting to help organizations promote quality improvement. Healthcare Policy. 2008; 4(2): 70-4.

[9] Mettler T, Rohner P. Performance Management in Health Care: The Past, the Present, the Future. Wirtschaftsinformatik. 2009; 2: 699-708.

[10] Voelker K, Rakich J, French G. The Balanced Scorecard in Healthcare Organizations: A performance measurement and Strategic Planning Methodology. Hospital topics: Res Perspectives on Healthcare. 2001; 79(3): 13-24. PMid: 11794940. http://dx.doi.org/10.1080/00185860109597908

[11] Inamdar N, Kaplan R, Bower M, Reynolds K. Applying the balanced scorecard in healthcare provider organizations. J Healthcare Manag. 2002; 47(3): 179-96. PMid: 12055900.

[12] Weiner BJ, Amick H, Lee SDY. Conceptualization and Measurement of Organizational Readiness for Change: A Review of the Literature in Health Services Research and Other Fields. Medical Care Res Rev. 2008; 65(4): 379-436. PMid: 18511812. http://dx.doi.org/10.1177/1077558708317802

[13] Mento AJ, Jones RM, Dirndorfer W. A change management process: grounded in both theory and practice. J Change Manag. 2002; 3: 45-59. http://dx.doi.org/10.1080/714042520

[14] Armenakis A, Harris S, Mossholder K. Creating readiness for organizational change. Human Relations. 1993; 46(3): 1-23.

[15] Armenakis AA, Harris SG. Reflections: our Journey in Organizational Change Research and Practice. J Change Manag. 2009; 9(2): 127-42. http://dx.doi.org/10.1080/14697010902879079

[16] Hagedorn HJ, Heideman PW. The relationship between baseline Organizational Readiness to Change Assessment subscale scores and implementation of hepatitis prevention services in substance use disorders treatment clinics: a case study. Implement Sci. 2010; 5(1): 1-12. PMid: 20546584. http://dx.doi.org/10.1186/1748-5908-5-46

[17] Weiner BJ. A theory of organizational readiness for change. Implement Sci. 2009; 4(67): 1-9.

[18] Holt DT, Helfrich CD, Hall CG, Weiner BJ. Are You Ready? How Health Professionals Can Comprehensively Conceptualize Readiness for Change. J Gen Intern Med. 2009; 25(Suppl1): 50-5. PMid: 20077152. http://dx.doi.org/10.1007/s11606-009-1112-8

[19] Damschroder L, Aron DC, Keith RE, Kirsh SR, Alexander JA, Lowery JC. Fostering implementation of health services research findings into practice: a consolidated framework for advancing implementation science. Implement Sci. 2009; 4(50): 1-15.

[20] Lehman W, Greener J, Simpson D. Assessing organizational readiness for change. J Substance Abuse Treatment. 2002; 22: 197-209. http://dx.doi.org/10.1016/S0740-5472(02)00233-7

[21] Bouckenooghe D, Devos G, Van Den Broeck H. Organizational Change Questionnaire-Climate of Change, Processes, and Readiness: Development of a New Instrument. J Psychol. 2009; 143(6): 559-99. PMid: 19957876. http://dx.doi.org/10.1080/00223980903218216

[22] Helfrich C, Li Y-F, Sharp ND, A. S. Organizational readiness to change assessment (ORCA): Development of an instrument based on the Promoting Action on Research in Health Services (PARiHS) framework. Implement Sci. 2009; 4(38). PMid: 19594942. 
[23] Stake RE. Case studies. Handbook of Qualitative Research. In: Lincoln NKDaYS, editor. New York: Sage Publications. 1994; 435-54.

[24] Armenakis AA, Bernerth JB, Pitts Walker HJ. Organizational change recepients' beliefs scale: Development of an assessment instrument. J Appl Behav Sci. 2007; 43: 481-505. http://dx.doi.org/10.1177/0021886307303654

[25] Greenhalgh T, Robert G, Macfarlane F, Bate P, Kyriakidou O. Diffusion of Innovations in Service Organizations: Systematic Review and Recommendations. Milbank Q. 2004; 82(4): 581-629. PMid: 15595944. http://dx.doi.org/10.1111/j.0887-378X.2004.00325.X

[26] Hsieh H-F, Shannon S. Three Approaches to Qualitative Content Analysis. QHR. 2005; 15(9): 1277-88. doi: 10.1177/1049732305276687. http://dx.doi.org/10.1177/1049732305276687

[27] Elo S, Kyngas H. The qualitative content analysis process. J Adv Nurs. 2008; 62(1): 107-15. PMid: 18352969. http://dx.doi.org/10.1111/j.1365-2648.2007.04569.x

[28] Bradley E, Curry L, Devers K. Qualitative Data Analysis for Health Services Research: Developing Taxonomy, Themes, and Theory. Health Res Educ Trust. 2007; 1758-72. http://dx.doi.org/10.1111/j.1475-6773.2006.00684.x

[29] Holt DT, Armenakis AA, Harris SG, Feild HS. Readiness for organizational change: The systematic development of a scale. J Appl Behav Sci. 2007; 43(2): 232-55. http://dx.doi.org/10.1177/0021886306295295

[30] Miles MB, Huberman M. Qualitative Data Analysis: A Sourcebook of New Methods 2ed. Beverly Hills, CA: Sage Publications. 1994.

[31] Blais M, Martineau S. L’analyse inductive générale: description d’une démarche visant à donner un sens à des données brutes. Recherches qualitatives. 2006; 26(2): 1-18.

[32] Patton MQ. Enhancing the Quality and Credibility of Qualitative Analysis. Health Services Research. 1999; 34(5): 1189-208. PMid: 10591279.

[33] Devers KJ. How Will We Know “Good” Qualitative Research When We See It? Beginning the Dialogue in Health Services Research. Health Services Research. 1999; 34(5): 1153-88. PMid: 10591278.

[34] Damanpour F. Organizational Innovation: A Meta-Analysis of Effects of Determinants and Moderators. Acad Manag J. 1991; 34: 555-90. http://dx.doi.org/10.2307/256406

[35] Bandura A. Self-efficacy mechanism in human agency. Am Psychol. 1982; 37(2): 122-47. http://dx.doi.org/10.1037/0003-066X.37.2.122

[36] Rafferty AE, Simons RH. An Examination of the Antecedents of Readiness for Fine-Tuning and CorporateTransformation Changes. J Bus Psychol. 2006; 20(3): 325-50. http://dx.doi.org/10.1007/s10869-005-9013-2

[37] Ijaz S, Vitalis A. Resistance to Organizational Change: Putting the Jigsaw Together. Int Rev Bu Res Papers. 2011; 7(3): 112-21.

[38] Pardo Del Val M, Martínez Fuentes C. Resistance to change: a literature review and empirical study. Manag Decision. 2003; 41(2): 148-55. http://dx.doi.org/10.1108/00251740310457597

[39] Zairi M, Jarrar Y. Measuring organizational effectiveness in the NHS: management style and structure bestpractices. TQM. 2001; 12(7, 8): 882-9.

[40] Bouckenooghe D. What is crucial in developing a positive attitude toward change? The role of content, context, process and individual variables in understanding readiness for change [dissertation]. Gent University. 2008; 400.

[41] Armenakis AA, Harris SG. Crafting a change message to create transformational readiness. J Organ Change Manag. 2002; 15: 169-83. http://dx.doi.org/10.1108/09534810210423080

[42] Rafferty AE, Jimmieson NL, Armenakis AA. Change Readiness: A Multilevel Review. J Manag. 2013; 39(1): 110-35. http://dx.doi.org/10.1177/0149206312457417

[43] Marshall MN, Shekelle PG, Davies HTO, Smith PC. Public reporting on quality in the United States and the United Kingdom. Health Affairs. 2003; 22(3): 134-48. PMid: 12757278. http://dx.doi.org/10.1377/hlthaff.22.3.134

[44] Barr JK, Boni CE, Kochurka KA, Nolan P, Petrillo M, Sofaer S, et al. Public reporting of hospital patient satisfaction: The Rhode Island experience. Health Care Financ R. 2002; 23(4): 51-70. PMid: 12500470.

[45] Marshall MN, Hiscock J, Sibbald B. Attitudes to the public release of comparative information on the quality of general practice care: qualitative study. BMJ. 2002; 325(7375): 1278-81. PMid: 12458248. http://dx.doi.org/10.1136/bmj.325.7375.1278

[46] Mannion R, Davies HTO. Reporting health care performance: learning from the past, prospects for the future. J Eval Clin Pract. 2002; 8(2): 215-28. PMid: 12180369. http://dx.doi.org/10.1046/j.1365-2753.2002.00331.x

[47] De Lancer Julnes P, Holzer M. Promoting the utilization of performance measures in public organizations: an empirical studyof factors affecting adoption and implementation Pub Adm Rev. 2001; 61(6): 693-708.

[48] Gross P, Braun B, Kritchevsky S, Simmons B. Comparison of clinical indicators for performance measurement of health care quality: a cautionary note. British J Clin Governance. 2000; 5(4): 202-11. 
[49] Whelan-Barry KS, Gordon JR, Hinings CR. Strengthening organizational change processes: Recommendations and implications from a multilevel analysis. J Appl Behav Sci. 2003; 39: 186-207. http://dx.doi.org/10.1177/0021886303256270

[50] Kotter J. Leading change: Why transformation efforts fail. Harvard Bus Rev. 1995; 73: 59-67.

[51] Wise GC, Alexander JA, Green LA, Cohen GR, Koster CR. Journey toward a Patient-Centered Medical Home: Readiness for Change in Primary Care Practices. Milbank Q. 2011; 89(3): 399-424. PMid: 21933274. http://dx.doi.org/10.1111/j.1468-0009.2011.00634.x

[52] Ferlie EB, Shortell SM. Improving the Quality of Helath Care in the United Kingdom and the United States: A Framework for Change. Milbank Q. 2001; 79(2): 281-315. http://dx.doi.org/10.1111/1468-0009.00206

[53] Lemire M, Demers-Payette O, Jefferson-Falardeau J. Dissemination of performance information and continuous improvement: a narrative systematic review. J Health Organ Manag. 2013; 27(4): 449-78. PMid: 24003632. http://dx.doi.org/10.1108/JHOM-08-2011-0082

[54] Damschroder L, Goodrich D, Robinson C, Fletcher C, Lowery J. A systematic exploration of differences in contextual factors related to implementing the MOVE! weight management program in VA: A mixed methods study. BMC Health Serv Res. 2011; 11: 248. PMid: 21961925. http://dx.doi.org/10.1186/1472-6963-11-248

[55] Shaw RJ, Kaufman MA, Bosworth HB, Weiner BJ, Zullig LL, Daniel Lee S-Y. Organizational factors associated with readiness to implement and translate a primary care based telemedicine behavioral program to improve blood pressure control:the HTN-IMPROVE study. Implement Sci. 2013; 8(106): 1-13.

[56] Weiner BJ, Alexander JA, Shortell SM. Leadership for quality improvement in health care; empirical evidence on hospital boards, managers, and physicians. Med Care Res Rev. 1996; 53(4): 397-416. PMid: 10162958. http://dx.doi.org/10.1177/107755879605300402

[57] Moynihan DP, Pandey SK. The Big Question for Performance Management: Why Do Managers Use Performance Information? JPAM. 2010; 20: 849-66.

[58] Weiner BJ, Haynes-Maslow L, Kahwati LC, Kinsinger LS, Campbell MK. Implementing the MOVE! weight-management program in the Veterans HealthAdministration, 2007-2010: a qualitative study. Prev Chronic Dis. 2012; 9: 1-13. http://dx.doi.org/10.5888/pcd9.110127.

[59] Damschroder LJ, Lowery JC. Evaluation of a large-scale weight management program using the consolidated framework for implementation research (CFIR). Implement Sci. 2013; 8(51): 1-17.

[60] Weiner BJ, Belden CM, Bergmire DM, Johnston M. The meaning and measurement of implementation climate. Implement Sci. 2011; 6(78): 1-12. http://dx.doi.org/10.1186/1748-5908-6-78

[61] Yin R. Case study research: design and methods. London: Sage Publications. 2003.

[62] Guba E, Lincoln Y. Fourth generation evaluation. Newbury Park: Sage Publications. 1989. 